
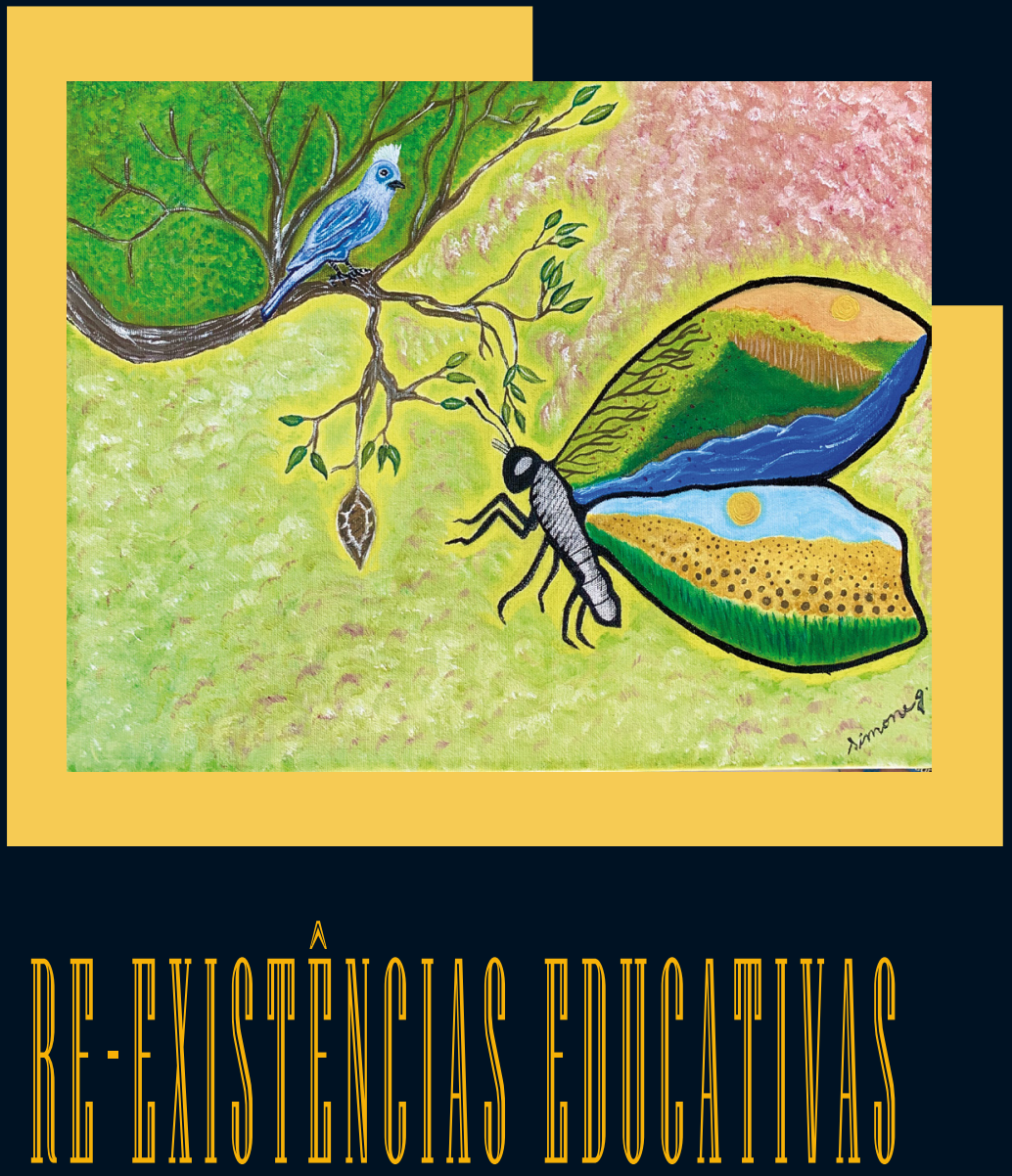

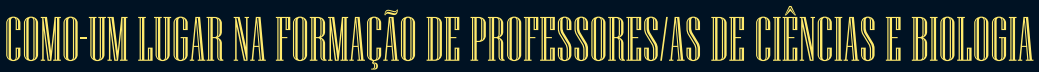

Organizadores:

Sandro Prado Santos

Gustavo Lopes Ferreira

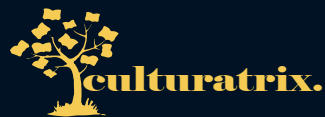




\section{RE-EXISTÂNCIAS EDUCATIVAS}

- CONO-JM LUGAR NA PORMAÇOO DE PROPLSSORES/AS DE CIENCLAS E BIOLOGIA - 


\section{Editora Culturatrix.}

| publicações acadêmicas |

Editora chefe

Rosa Maria Ferreira da Silva

\section{Editor assistente}

Cairo Mohamad Ibrahim Katrib (UFU)

\section{Conselho Editorial}

Eliane Martins de Freitas (UFG - Catalão)

Emília Saraiva Nery (FACEMA)

Euclides Antunes de Medeiros (UFT)

Floriana Rosa da Silva (SRE-MG)

lara Toscano Correia (UFU)

Helena Maria Ferreira (UFLA)

Luís André Nepomuceno (UNIPAM)

Marcos Antônio de Menezes (UFG)

Maria Clara Tomaz Machado (UFU)

Miguel Rodrigues de Sousa Neto (UFMS)

Olívia Cormineiro (UFT)

Regma Maria dos Santos (UFG - Catalão)

Remi Castioni (UnB)

Renato Jales Silva Júnior (UFMS)

Ricardo Vidal Golovaty (IFG)

Simone Aparecida dos Passos (UFU)

Tadeu Pereira dos Santos (UNIR) 


\section{RE-EXISPAENCIAS EDUCATIVAS}

- COMO-UW LUGAR NA PORMAÇ̃O DE PRORESSORES/AS DE CIENCIAS E BIOLOGIA -

Organizadores:

Sandro Prado Santos

Gustavo Lopes Ferreira

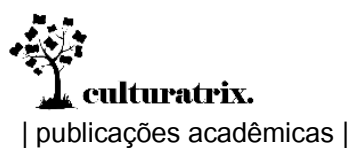


Copyright 2020 @ Sandro Prado Santos, Gustavo Lopes Ferreira, 2020.

Todos os direitos reservados.

*O conteúdo desta obra, bem como sua originalidade, revisão gramatical e ortográfica são de inteira responsabilidade dos autores.

Editora de Publicação: Rosa Maria Ferreira da Silva

Projeto Gráfico e Capa: Igor Ferreira

Ilustração: Simone Gomes Firmino

Diagramação: Studio Escrita \& Criação

Dados Internacionais de Catalogação na Publicação (CIP)

Nelson Marcos Ferreira - CRB-6 / 3074

R281e Re-existências educativas - como-um lugar na formação de professores/as de ciências e biologia / organizadores: Sandro

Prado Santos, Gustavo Lopes Ferreira ; ilustração da capa:

Simone Gomes Firmino. -- Uberlândia : Culturatrix, 2020.

$64 \mathrm{p}$.

ISBN: 978-65-86889-05-5 (e-book)

DOI: 10.4322/978-65-86889-05-5

Formato: Digital

Extensão: PDF

Inclui bibliografia.

1. Biologia. 2. Ciências. 3. Formação de professores. 4. Pandemia. 5. Resistências. I. Santos, Sandro Prado, 1982-, (org.). II. Ferreira, Gustavo Lopes, 1987-, (org.). III. Firmino, Simone Gomes, (ilust.).

CDU: 
Dedicamos este caderno aos professores/as que na pandemia do novo coronavírus tiveram que se reinventar, mostrando que é possível re-existir em tempos duros.

Tudo vai passar! 


\title{
SUMÁRIO
}

\author{
PREFÁCIO
}

SOPROS DE VIDA, ENCANTAMENTOS E URGÊNCIAS NA

FORMAÇÃO DE PROFESSORES/AS DE CIÊNCIAS E BIOLOGIA

Sandro Prado Santos

A PANDEMIA DE COVID-19 E O DESAFIO DE AULAS REMOTAS

PARA A EDUCAÇÃO BÁSICA

Fátima Lucia Dezopa Parreira

PRIORIDADES NO ENSINO EM CONTEXTO DE PANDEMIA: 17

DILEMAS E DIÁLOGOS

Ana Isa Marquez Rocha Machado

FORMAÇÃO INICIAL DOCENTE NA TEMPORÁRIA INFLEXÃO ATUAL

Viviane Rodrigues Alves de Moraes

ESTÁGIOS E TRÂNSITOS NA FORMAÇÃO INICIAL EM CIÊNCIAS E 25 BIOLOGIA

Matheus Moura Martins

MATERIAL DIDÁTICO: EXPERIÊNCIA NO ENSINO

CONTEXTUALIZADO E SIGNIFICATIVO DE BIOQUÍMICA E GENÉTICA

Luciana Karen Calábria e Alexandre Azenha Alves de Rezende

DESAFIOS NA FORMAÇÃO, CONVERSÃO E ATUAÇÃO DOCENTE

Alexandre Azenha Alves de Rezende e Luciana Karen Calábria

OS PROGRAMAS DE FORMAÇÃO INICIAL DE PROFESSORES DE CIÊNCIAS: POSSIBILIDADES PARA ARTICULAÇÃO ENTRE A EDUCAÇÃO BÁSICA E O ENSINO SUPERIOR

Ariane de Souza Siqueira 
O PROGRAMA INSTITUCIONAL DE BOLSA DE INICIAÇÃO À

DOCÊNCIA - PIBID: POLÍTICA DE FORMAÇÃO SOB ATAQUE

Renata Carmo-Oliveira

RE-EXISTÊNCIAS NA FORMAÇÃO DE PROFESSORES DE CIÊNCIAS

E BIOLOGIA NO CONTEXTO DOS INSTITUTOS FEDERAIS

Gustavo Lopes Ferreira

MEMÓRIAS DA INFÂNCIA À PROFISSÃO DOCENTE: HISTÓRIAS DE UMA PROFESSORA DE BIOLOGIA

Tiessa Lorraine Miguel da Silva

A ASSOCIAÇÃO BRASILEIRA DE ENSINO DE BIOLOGIA (SBENBIO)

E A FORMAÇÃO DE PROFESSORAS E PROFESSORES: POR ONDE CAMINHAMOS

Leandro Duso

O SISTEMA CFBIO/CRBIOS E O BIÓLOGO-EDUCADOR

Atenágoras Carvalhais e Mariana Telles 
PREFÁCIO

\section{SOPROS DE VIDA, ENCANTAMENTOS E URGÊNCIAS NA FORMAÇÃO DE PROFESSORESIAS DE CIÊNCIAS E BIOLOGIA}

Na língua dos pássaros uma expressão tinge a seguinte.

Se é vermelha tinge a outra de vermelho.

Se é alva tinge a outra dos lírios da manhã.

É língua muito transitiva a dos pássaros.

Não carece de conjunções nem de abotoaduras.

Se comunica por encantamentos.

E por não ser contaminada de contradições

A linguagem dos pássaros

Só produz gorjeios.

(Manoel de Barros. Retrato do artista quando coisa.

Rio de Janeiro: Record, 1998).

Um evento on-line, encontros, muitas re-existências, intensões, encantamentos, potencialidades de (trans)mutações, criação de um caderno-re-existência... que se compõe com pequenos e desafiadores exercícios de escrita, educativos, atravessados por reflexões teóricas, narrativas, experienciações, lutas, afetos, sensibilidades, inter(in)venções, desafios, diferentes espaços-tempos formativos que re-existem, acolhem e tornam possível a educação e a formação em Ciências e Biologia.

Um acon-tecimento coletivo em 12 textos entrelaçados, numa aposta como-um, ao fazer e ensinar ciências e Biologias; aos estágios supervisionados; ao PIBID; aos institutos federais; a SBEnBio e ao CRBio-04; e criados pelas pessoas convidadas 
do evento "Re-existências educativas como-um lugar na formação de professores/as de Ciências e Biologia", a saber: professores/as de Ciências e Biologia da rede pública de educação básica; professores/as de institutos federais e ensino superior. Um encontro on-line, situado no contexto de um processo de isolamento pandêmico, oferecido pelo Instituto de Ciências Exatas e Naturais do Pontal (ICENP/UFU) a partir de apoios da Pró-Reitoria de Extensão e Cultura (PROEXC/UFU) e do Conselho Regional de Biologia da $4^{\mathrm{a}}$ região - CRBio-04.

Temos uma feitura de textos que povoa a formação de professores/as de Ciências e Biologia com uma multiplicidade polifônica, ou seja, diferentes vozes, cantos, vidas, conexões, alianças, saberes e sabores que se metamorfoseiam e ecoam de diferentes espaços, trajetórias e tempos formativos, fazendo proliferar a provocação de experimen-torções, com disposição e fôlego, ao campo das vulnerabilidades a que estão expostas a profissão docente e a educação em Ciências e Biologia no contexto dos atuais projetos, diretrizes curriculares e políticas educacionais brasileiras; políticas que reclamam de nós uma implicação em/com apostas, resistências e possiblidades da/na/com a formação docente.

Os textos iniciam com os desafios e os dilemas instalados pela pandemia de COVID-19 em contextos da escola de educação básica e dos institutos federais de ensino, no entroncamento entre os diálogos para se pensar movimentos de re-invenção do tempo-lugar da escola e do exercício da 
docência; e os impactos nas políticas, programas de formação e nas vivências pedagógicas com atividades práticas e estágios supervisionados.

As forças de resistências da formação inicial de professores/as são acionadas diante da temporária inflexão atual brasileira, marcada pelas constantes e reiteradas ameaças às instituições democráticas e à qualidade da educação básica e superior, nos encorajando na investidura em mobilizações e alianças entre as instituições acadêmicas e dos/as profissionais da educação básica.

No desafio de um pensar - fazer ciência e ensinar ciência, temos as experimentações de um devir-professor/a formador/a no ensino de bioquímica e de genética que se ramificam em narrativas carto-gráficas da identidade docente; da pesquisa em educação; da vivência do método científico; entrelaçando com a criação de materiais didáticos, aulas práticas experimentais virtuais, modelos, jogos, mídias visuais, mapas conceituais, e, se conjugam em trânsitos pelo laboratório de ensino e pelas escolas públicas.

No contexto de insurgências de políticas públicas que fomentam a aproximação da docência aos espaços da rede escolar pública de educação básica temos a centralidade do Programa Institucional de Bolsas de Iniciação à Docência (PIBID), a partir das experiências formativas de uma professora supervisora e de uma professora que foi coordenadora de área e agora coordenadora institucional do programa. Esses dois 
textos marcam a relevância do estreitamento dos laços entre a escola e o PIBID, apesar dos ataques e disputas, e, delineiam as interfaces possíveis com os contextos escolares, tais como: alfabetização científica, enfoque CTSA, estudos teóricometodológicos, culturais e das diferenças.

$\mathrm{Na}$ esteira dos itinerários formativos de professores/as de Ciências e Biologia, somos convidados/as a acampar e se encantar com um outro locus formativo de re-existência - os institutos federais. Seremos apresentados/as a um modo de inter(in)venções no processo de formação inicial de professores/as que tecem relações entre a prática pedagógica e o fazer investigativo, as narrativas autobiográficas. Uma experimentação potente e que nos será contada por uma professora de biologia, revisitando memórias e histórias da infância à profissão docente, singularizando-a.

Finalizando essa trama de composição textual e seus atravessamentos com a formação docente em Ciências e Biologia, teremos um diálogo com a Associação Brasileira de Ensino de Biologia (SBEnBio) e com o Conselho Regional de Biologia da $4^{\text {a }}$ Região (CRBio-04), enunciando a relevância e o fomento dessas instituições na geração e preservação da História da Ciência e de profissionais relacionados seja o/a professor/a de Ciências e Biologia e o Biólogo/a educador/a.

Aqui encontrei com textos que me convidaram a fortalecer políticas formativas e curriculares no campo da docência, sobretudo, aliada com o espaço da escola pública de 
educação básica. Aceitei o convite e estendo-o a você, leitor/a: venha! Dê-lírios, mergulhe-se nesse caderno-re-existência, de lutas e resistências, ele pode ser potente diante dos ataques e disputas que estamos atravessando na formação de professores/as e na educação escolar brasileira. Agradecemos as/aos professoras/es que aceitaram o convite, acreditaram, confiaram nessa produção coletiva com encantamentos e gorjeios, assim como os pássaros no poema de Manoel de Barros: Alexandre Azenha; Luciana Calábria; Gustavo Ferreira; Ana Isa; Renata de Oliveira; Fátima Dezopa; Matheus Moura; Leandro Duso, Viviane Moraes; Ariane de Souza; Tiessa Lorraine; Atenágoras Carvalhais e Mariana Telles. Gratidão!

Sandro Prado Santos Uberlândia/MG, 


\section{A PANDEMIA DE COVID-19 E O DESAFIO DE AULAS REMOTAS PARA A EDUCAÇÃO BÁSICA}

Fátima Lucia Dezopa Parreira

A pandemia de COVID-19 tem produzido transformações nos modos de estar em sociedade, especialmente em decorrência das recomendações de afastamento social, a fim de se evitar o contágio entre as pessoas. Esse contexto trouxe grandes desafios a serem somados a outros tantos, que cotidianamente afetam a Educação Básica e mobilizam a atenção de pesquisadores/as, professores/as e outros campos da sociedade civil. Este texto pretende refletir sobre os desafios e possibilidades de reexistências do Ensino de Biologia, no contexto da pandemia, considerando as peculiaridades da escola pública, como políticas equivocadas, escassez de recursos materiais e humanos, além da precarização das condições financeiras dos/as estudantes.

Poderia, intempestivamente, afirmar que a formação, desde a graduação em Ciências Biológicas e, posteriormente, nos cursos de mestrado e doutorado em Educação não legaram saberes capazes de orientar a navegação por esse tempo-lugar da escola em contexto de pandemia. Mas, sim a academia, juntamente com a experiência na docência da educação básica e a aproximação com grupos que se ocupam dos direitos das 
pessoas e com a defesa da diferença como condição de existência, conferem aportes para pensar a educação em tempos de crise. Ora, a pandemia de COVID-19 tem se configurado como uma das maiores crises a afetar a humanidade e seus reflexos se fazem perceber em todos os campos da atividade humana. Da economia à arte, da educação às relações pessoais e familiares, o mundo se curva à pandemia.

Nesse sentido, os aportes oferecidos pela academia e pela experiência de vida cidadã e profissional contribuem para superar o temor de um lugar do não-saber sobre a pandemia e pouco saber sobre as tecnologias que fazem a mediação no ensino remoto. Mesmo em cenário incerto e inusitado pelo desconhecimento do vírus Sars-CoV-2, a formação profissional e a experiência permitem a compreensão dos fatos científicos e a reflexão sobre as questões sociais que se desenrolam ao tempo da pandemia. A compreensão dos saberes da ciência, descortinando genomas, orientando medidas de prevenção e produzindo protocolos de ação, bem como a possibilidade de refletir acerca dos efeitos da pandemia sobre os diferentes grupos sociais e sobre a importância do estabelecimento de políticas públicas voltadas ao combate à doença e ao acolhimento das pessoas socialmente mais fragilizadas fortalecem a possibilidade de mediar a discussão com os/as estudantes. 
Uma vez assumido o lugar do não-saber, assim como Joseph Jacotot, o "mestre ignorante" trazido por Jacques Rancière (RANCIÈRE, 2015) e superado o impasse inicial produzido pela temor de discriminar estudantes sem acesso a equipamentos e Internet, pela convicção de que, de que a discriminação estava posta, uma vez que as escolas privadas já estavam com a dinâmica do ensino remoto há algum tempo, foi possível o início das aulas remotas, com o cuidado de disponibilizar material impresso para estudantes sem acesso rotineiro à Internet.

A escola torna-se o lugar do encontro pela tela do computador, do tempo cuidadosamente cronometrado, do material didático confeccionado e enviado pela Secretaria de Estado de Educação (SEE-MG). Torna-se a escola, como nunca antes, o lugar do controle dos saberes e fazeres de docentes e estudantes. Controle decorrente por um refinamento das técnicas de reclusão, como sugere Giles Deleuze (1992); controle que se dá não mais pela contenção física, mas por técnicas de monitoramento mediadas por câmeras, microfones e registros de acessos às plataformas digitais.

Trazer Rancière (2015) a essa discussão não implica em excluir do processo educacional, professoras e professores, mas, antes em pensar outros movimentos no exercício da docência, movimentos de uma educação emancipatória, alijando sim o papel de quem explica, para o papel de quem oportuniza situações de discussão de uma Biologia que se 
ocupa dos contextos, dos aspectos sociais e culturais que afetam a sociedade; uma Biologia que não se limite ao detalhamento tecnicista de estruturas, funções e sintomas, mas, que sobretudo se ocupe das pessoas. Com Deleuze (1992), a denúncia do controle da ação docente e dos/as estudantes, no cenário atual, por meio de mídias digitais. Re-existências de uma escola que se reinventa no contexto da pandemia.

\section{REFERÊNCIAS}

DELEUZE, Gilles. Crítica e clínica. São Paulo: Editora 34, 1992.

RANCIĖRE, Jacques. O mestre ignorante: cinco lições sobre a emancipação intelectual. $3^{a}$ ed. Tradução de Lílian do Valle. Belo Horizonte: Autêntica, 2015. 


\section{PRIORIDADES NO ENSINO EM CONTEXTO DE PANDEMIA: DILEMAS E DIÁLOGOS}

\section{Ana Isa Marquez Rocha Machado}

Parece óbvio começar esse relato de experiência afirmando que este momento de pandemia é sem precedentes para a humanidade, em especial, para a nossa geração. Mas é imprescindível que eu comece o texto dessa forma, pois não há trajetória ou formações pedagógica e profissional que nos tenham preparado para este momento. Tivemos que nos reinventar enquanto escola e seres humanos em poucas semanas. Quanta insegurança...

Contudo, estamos aqui, eu, colegas docentes e equipe pedagógica, nesse papel importante em momentos normais, mais importante ainda neste cenário caótico e inédito. Sou bacharel e licenciada em Ciências Biológicas e desde 2013 sou docente do Instituto Federal de Educação, Ciência e Tecnologia do Triângulo Mineiro - Campus Uberaba em vários cursos, entre eles o de Licenciatura em Ciências Biológicas. Ministro as unidades curriculares da área de Botânica e atuo como colaboradora nas atividades de práticas pedagógicas do curso. Este texto também se baseia na minha experiência como coordenadora do referido curso entre 2016 e 2018 e, entre janeiro e agosto de 2020. 
O título deste relato traz as duas palavras de ordem nesse período: dilemas e diálogos. Minha experiência profissional na pandemia tem sido um pouco particular da vivida pela maioria dos colegas de outras instituições, visto que no IFTM suspendemos as atividades em 18 de março e as reiniciamos, de forma remota, já no dia 24 do mesmo mês. Esse intervalo de dias serviu para a articulação da gestão com os coordenadores de curso no estabelecimento de diretrizes para o início das atividades totalmente não presenciais, denominadas de ensino remoto.

Os dilemas estão sendo diários e conforme amadurecemos no ensinar eles mudam, mas não deixam de existir. O primeiro dilema foi, naturalmente, sobre a efetividade do ensino remoto. Começamos as atividades de forma rápida e o ponto positivo foi que os nossos alunos continuaram em comunicação conosco. Conseguimos continuar a acolhê-los, manter a comunicação com a maioria deles, e, de alguma forma, manter viva a escola na rotina do aluno e da sua família. Ao mesmo tempo, passamos a lidar com questões que se intensificaram enormemente com o passar dos meses, como: Quais são as condições tecnológicas, ergonômicas e de espaço dos nossos alunos para o ensino remoto? Quais são as condições psicológicas dos alunos e de suas famílias para a intensidade da convivência imposta pela pandemia? E quando me peguei preocupadíssima em analisar a situação dos alunos, 
percebi que as mesmas perguntas precisavam ser feitas também sobre os docentes e a equipe pedagógica.

Após o sacrifício de todos para a implantação do ensino remoto, a dificuldade em estabelecer indicadores de efetividade deste segue, pois a diversidade de características de cada colega e de cada aluno é infinita. A heterogeneidade foi e é marcante. De um lado docentes muito rígidos e de outro, docentes que conseguiram lembrar que, neste momento, algumas exigências, critérios ou atividades não fazem mais sentido. Ao mesmo tempo observa-se alguns alunos e famílias felizes por continuarem a ter a escola na rotina, mas outros envolvidos em contextos que o espaço que a escola tradicional está exigindo não existe ou diminuiu consideravelmente. A todo momento luta-se para que o processo não seja excludente, mas ainda assim, isso tem sido impossível.

Na Licenciatura o impacto em vivências pedagógicas foi profundo. Os ingressantes conheceram a instituição, alguns docentes e usufruíram disso por 10 dias, tendo que se adaptar ao ensino remoto ao mesmo tempo que se acostumam com a nova realidade de serem alunos do ensino superior. A angústia e o desapontamento também são marcantes, visto que alunos da segunda metade do curso lidam com a suspensão dos seus estágios curriculares supervisionados e a realidade de que não se graduarão no tempo previsto. Ao mesmo tempo o adiamento dos programas de formação de professores, Pibid e Residência Pedagógica, a suspensão, mesmo que provisória, dos editais de 
bolsas acadêmicas - monitoria, projetos de extensão e de pesquisa, bagunçaram os planos e tiraram a oportunidade dos alunos concorrerem a bolsas acadêmicas no tempo planejado, as quais, em muitos casos, subsidiam sua permanência no curso.

São tantos elementos e fatores externos que, às vezes, é difícil nos atermos a aspectos como aprovação e sucesso dos alunos em unidades curriculares, cumprimento de dias letivos e cumprimento de cargas horárias. Os dilemas são tão numerosos que ainda não conversamos neste texto sobre a importância fundamental das aulas práticas (esse é um ponto crucial em várias unidades curriculares, ao meu ver), direitos autorais de imagem e material elaborados pelos professores e disponibilizados aos alunos, capacitação tecnológica e pedagógica sobre ensino mediado por tecnologias para a equipe pedagógica, dentre outros. Questões que vêm sendo bastante discutidas e trabalhadas no IFTM.

Em meio a tantos dilemas, somente o diálogo permitirá entendermos a realidade do outro, ter noção do impacto das diferentes realidades de cada um nesse processo e, mesmo à distância, acolher e abraçar nosso aluno e nosso colega através da educação. 


\section{FORMAÇÃO INICIAL DOCENTE NA TEMPORÁRIA INFLEXÃO ATUAL}

Viviane Rodrigues Alves de Moraes

Quando iniciei a carreira docente, nos anos 80, ainda não era graduada, mas trazia na bagagem um ensino médio profissionalizante (Magistério). Nesse primeiro período passei profissionalmente, por grandes reformas educativas, centradas na estrutura dos sistemas escolares e do currículo; nos anos 90 , já graduada, o foco das políticas públicas dedicou atenção especial às organizações escolares, ao seu funcionamento, administração e gestão.

A partir dos anos 2000, os programas internacionais de avaliação do desempenho escolar passaram a focar no problema das aprendizagens ditando os encaminhamentos para a formação docente. Foi nessa época que decidi pelo retorno à academia, fiz mestrado em área distinta da Educação, e depois, retomei meu foco optando pelo Doutorado nessa área. Após ter ingressado na Universidade como docente, pude perceber que, embora a formação docente seja o objetivo destas políticas públicas, outros problemas e preocupações fazem com que o foco no professor seja periférico. Temos visto, no entanto, no início deste século, que a educação como função social, readquiriu uma posição de destaque nas visões estratégicas do futuro coletivo, colocando o professor e sua formação no centro 
das atenções, o que pode provocar, paradoxalmente, de acordo com Nóvoa (2011), controles estatais e científicos que podem implicar em uma desvalorização de suas competências e autonomia profissional. Infelizmente, nos últimos anos é o que temos observado, pois a última resolução (CNE, 20/12/2019), que traz as novas diretrizes para a Formação Inicial de Professores, é diretiva e não apresenta a abrangência das anteriores, embora haja pontos positivos como o aumento das horas destinadas à formação e diretrizes para que os cursos voltem-se para a prática nas escolas desde o início da graduação. Por outro lado, trazem uma flexibilização da carga horária (complementação pedagógica) para bacharéis, que passou de 1.400 horas para 760 horas. E o que quer dizer tudo isso? Que a formação docente sempre esteve sob a tutela do estado e que nossos currículos de formação se estruturam a partir destas resoluções, portanto, impactam na formação inicial docente.

Dentro desse contexto político de formação, destaco que existe o percurso humano do formador. Creio que a produção de sentido em torno da formação docente tenha sido sempre minha meta, percebendo que a escola não é apenas um espaço de conhecimento, cultura e de socialização, é também um lugar de construção da identidade pessoal e profissional do futuro professor. Nessa linha, a desconstrução de significados sobre papéis de professor e aluno tem constituído objetivos durante o estágio para a redefinição e/ou produção de novos 
sentidos sobre ser professor. Uma desconstrução que esbarra em crenças histórico/culturais muito arraigadas, que, portanto, necessita de um percurso formativo analítico e crítico, capaz de provocar a reflexão consciente, e por consequência, impactar a produção de sentidos, posto que estes são mutáveis, afetivocognitivos e constituídos historicamente a partir da dinâmica das relações sociais que os licenciandos estabelecem dentro das escolas.

$\mathrm{Na}$ atual inflexão temporal que estamos vivendo as mudanças nos atravessam, diversificam os canais de comunicação, informação e conhecimento; questionam a pertinência de fórmulas arcaicas para operar em novos modelos organizacionais; permutam as hierarquias de texto e imagem, mudam os critérios que determinam vigência e anacronismo, importância e irrelevância, obrigando o sistema educacional a rever seus paradigmas clássicos (HOPENHAYN, 2006). De repente, sem preparação ou aviso, nosso vocabulário mudou e passou a incluir palavras como aula síncrona, distanciamento, plataforma, COVID19, máscara, chat, online, álcool em gel, entre outras, que também passaram a figurar no campo lexical das escolas. Os signos mudam, as fronteiras entre os papeis sociais de aluno, de professor, das famílias se rompem, dispostas a invadir o espaço umas das outras no cenário da atual pandemia. E nós, professores, como ficamos? 
Ficamos com a certeza de educar sempre foi e sempre será um ato relacional. Os melhores algoritmos não são capazes de compreender a diversidade das linguagens existentes em uma sala de aula, não percebem o brilho nos olhos do aluno que entende o que se the explica, e não substituem a temperatura do olhar, a postura corporal, os gestos, a entoação, o ritmo da fala de um professor (POMBO apud NÓVOA, 2011)

Creio que, o sonho de melhorias educacionais ainda permanece, em grande parte, nas mãos dos professores, portanto, uma sociedade que cuida de seu porvir coletivo não pode deixar de se preocupar com o bem-estar de seus docentes; de promover sua valorização social, e de zelar pelo avanço contínuo de seu desenvolvimento profissional.

\section{REFERÊNCIAS}

NÓVOA, Antônio. O Regresso dos Professores. Pinhais: Melo, 2011. HOPENHAYN, Martin. A educação na atual inflexão temporal: Uma perspectiva latino-americana. Revista PRELAC (Projeto regional de educação para a América latina e o caribe). № 2, Fev., p. 6-12, 2006. 


\section{ESTÁGIOS E TRÂNSITOS NA FORMAÇÃO INICIAL EM CIÊNCIAS E BIOLOGIA}

\section{Matheus Moura Martins}

O objetivo desse texto é compartilhar os diferentes estágios-momentos e trânsitos da minha trajetória de formação inicial no campo da docência em Ciências Biológicas. Na educação básica - enquanto aluno - as aulas de Ciências e Biologia me provocavam e arrastavam para o desejo de ser professor. Contudo, fui desencorajado a cursar a licenciatura, principalmente pelos discursos que desvalorizam a docência, e só após desistir do curso de Direito, tomei coragem para cursála. Nesse contexto, meu primeiro contato com a área de Educação, a formação de professores/as e com a escola pública de educação básica, na formação inicial, aconteceu no Estágio Supervisionado Curricular obrigatório, compondo participações em eventos escolares, regências, no planejamento de projetos, nos eventos da escola e em visitas técnicas, caracterizando momentos formativos de vivências e atravessamentos com histórias, saberes e práticas curriculares no/do campo oficial do ensino de biologia. (SELLES, et al., 2009). Com isso, fui experimentando a indissociabilidade entre teoria, prática e pesquisa na área de educação. Posteriormente, ingresso no Programa Institucional de Bolsas de Iniciação à Docência 
$(\mathrm{PIBID})^{1}$ subprojeto Biologia-Pontal. Neste espaço-tempo formativo vivenciei as possibilidades e potencialidades da produção de conhecimento e saberes escolares, defendendo a valorização dos espaços públicos de educação, bem como as contribuições da professora supervisora e do espaço da escola como campos de co-formação de professores/as.

Outros trânsitos aconteceram na participação e organização de eventos, sobretudo no IV EREBIO ${ }^{2}$ e no $\mathrm{V}$ $\mathrm{EREBIO}^{3}$, eles provocaram expansões, conquistas e aberturas que deram passagem às discussões de corpos, gêneros e sexualidades na minha atuação profissional e na pesquisa em educação. Nesse sentido, sob orientação do Prof. Dr. Sandro Prado Santos, me debruço na investigação "Ensino de Ciências e Biologia, Qual seu partido? Entre alinhamentos e fugas", resultando no meu trabalho final de um curso de licenciatura. Nosso propósito foi colocar em movimento os corpos, gêneros e sexualidades nas disciplinas escolares de Ciências e Biologia no encontro com as manobras "neofascistas" do Movimento Escola Sem Partido, apostando em experiências outras de uma educação em Ciências e Biologia, da recusa aos modelos fixos

\footnotetext{
Promovido pela CAPES que visa uma aproximação com o cotidiano das escolas públicas de educação básica e o os cursos de Licenciatura das Universidades.

${ }^{2}$ IV Encontro Regional de Ensino de Biologia. Os Encontros Nacionais e Regionais de Ensino de Biologia são uma iniciativa da Associação Brasileira de Ensino de Biologia (SBEnBio). Página oficial: https://sbenbio.org.br/. Acesso em: 20 ago. 2020.

${ }^{3}$ V Encontro Regional de Ensino de Biologia da Regional 04, Uberlândia, e VII Simpósio de Ciências Biológicas do Sudeste Goiano, Catalão - GO, ago. 2019. Nesse evento participei da comissão organizadora na função de monitor.
} 
e naturalizados das feminilidades, masculinidades, dos desejos e das práticas sexuais, na insistência em afirmar a potência dos corpos, gêneros e sexualidades como possibilidades de resistências. (SANTOS; MARTINS, 2018). Resultados que foram socializados no VII ENEBIO e I EREBIO ${ }^{4}$ Região Norte.

Dessa forma, as experiências e memórias dos trânsitos pelos estágios, eventos do campo do ensino de biologia, PIBID e as discussões na pesquisa em educação, fomentaram posicionamentos políticos de resistências no meu trabalho docente. Meu início de carreira na docência acontece em um momento atual brasileiro marcado por uma profunda crise política e econômica, com ameaças às instituições democráticas promovidas por grupos reacionários e neoliberais atacando direitos adquiridos, como os trabalhistas, saúde, educação e segurança pública, constituindo ameaças à qualidade da educação básica e superior e a formação de professores/as. Sendo assim, tal conjuntura demanda a mobilização e aliança das entidades acadêmicas e dos profissionais da educação básica e superior em investiduras na aproximação entre educação básica e ensino superior.

\footnotetext{
${ }^{4}$ VII Encontro Nacional de Ensino de Biologia e I Encontro Regional de Ensino de Biologia - Região Norte, Belém - PA, set. 2018.
} 


\section{REFERÊNCIAS}

SANTOS, Sandro Prado.; MARTINS, Matheus Moura. Ensino de Ciências e Biologia, Qual seu partido? Entre alinhamentos e fugas. In: Anais... VII Encontro Nacional de Ensino de Biologia/ I Encontro Regional de Ensino de Biologia, 2018, Belém - PA. Belém: IEMCI, UFPA, 2018. p. 3555-3565.

SELLES, Sandra Escovedo.; FERREIRA, Márcia Serra.; BARZANO, Marco Antonio Leandro.; SILVA, Elenita Pinheiro de Queiroz. (Org.). Ensino de Biologia: histórias, saberes e práticas formativas. Uberlândia: EDUFU, 2009. 


\section{MATERIAL DIDÁTICO: EXPERIÊNCIA NO ENSINO CONTEXTUALIZADO E SIGNIFICATIVO DE BIOQUÍMICA E GENÉTICA}

Luciana Karen Calábria

Alexandre Azenha Alves de Rezende

As práticas pedagógicas, a realidade do estudante, seu contexto social e cultural, bem como seus conhecimentos prévios são pontos de reflexão na vivência de um professor e auxiliam no pensar a docência com foco no ensino contextualizado e significativo.

O ensino de aspectos relacionados à Bioquímica e Genética, conteúdos extensos que possuem caráter interdisciplinar, depende da visualização de representações estruturais e fenômenos com abstração, uma vez que são apresentados pelos estudantes como temas de difícil entendimento. Nesse caso, os materiais didáticos são considerados uma estratégia eficiente para proporcionar significado e contextualização no processo de ensinoaprendizagem apropriado.

De fato, a construção do material didático poderia ser realizada pelo próprio docente na formação de professores/as; no entanto, na prática têm se observado que quando o estudante licenciando executa o planejamento, elaboração, execução e avaliação do material didático em criação, há a transposição 
didática. Neste contexto, o ensino dinâmico se faz presente e o estudante passa a pensar nas necessidades e dificuldades daqueles que utilizarão a ferramenta didática, inclusive considerando os aspectos regionais e culturais na contextualização do ensino, talvez até de um modo mais criativo e interativo do que o professor apresentaria em sala de aula. Além disso, Zierer (2017) afirma que a participação ativa na elaboração e construção de modelos didáticos tem efeitos psicológicos positivos nos estudantes, elevando sua autoestima e segurança, uma vez que há a valorização das suas ideias, produções e questionamentos.

Assim, desde 2014, a construção de materiais didáticos tem sido empregada como ferramenta de ensino de Bioquímica e Genética, comprovadamente eficiente, e facilitadora do ensino-aprendizado por meio da representação de conceitos ou da revisão de conteúdos teóricos, porém de forma mais dinâmica e interativa comparada com as aulas teóricas como única metodologia de ensino. A atividade de construção de material didático inclui a participação ativa dos estudantes, valorizando seus conhecimentos prévios e estimulando a pesquisa, a obtenção de novos dados e a construção do conhecimento.

Dentre os materiais didáticos que foram construídos pelos estudantes para o ensino de Bioquímica e Genética podemos citar as aulas práticas experimentais virtuais ou presenciais, modelos, jogos, mapas conceituais, textos complementares, 
mídias visuais, aprendizagem baseada em problemas e as tecnologias baseadas em informação. Essa atividade foi realizada durante os componentes curriculares "Bioquímica", "Genética" e "Oficina de Ciências e Biologia" e alguns dos materiais didáticos foram posteriormente doados ao Laboratório de Ensino do Curso de Ciências Biológicas da Universidade Federal de Uberlândia, Campus Pontal ou às escolas municipais e estaduais do município de Ituiutaba, MG.

Vale destacar os critérios que são impostos para a construção do material didático, os quais incluem a aplicabilidade em sala de aula, criatividade, originalidade, respeito a diversidade (inclusão) e durabilidade (sustentabilidade), dentre outros. A maioria dos materiais didáticos produzidos, até o momento, tentou atender aos critérios impostos, resultando em produtos testados em grupos internos, com legendas em braile e utilizando materiais recicláveis e de baixo custo.

As experiências positivas vividas na formação de professores/as utilizando a construção de material didático como ferramenta transformadora do conhecimento reforçam a importância de reflexões sobre a mudanças no processo de ensinar e aprender, uma vez que o material didático produzido pelo estudante passa de um modelo de transmissão para o de construção do conhecimento. Além disso, o emprego desta estratégia para o ensino-aprendizagem de Bioquímica e 
Genética também permitiu estimular os estudantes a desenvolverem habilidades, como autonomia, plasticidade e transformação, tão importantes no campo profissional nos tempos atuais.

\section{REFERÊNCIAS}

ZIERER, Maximiliano de Souza. A construção e a aplicação de modelos didáticos no ensino de Bioquímica. Revista de Ensino de Bioquímica, v. 15, p. 202-211, out. 2017. doi: https://doi.org/10.16923/reb.v15i0.691. 


\section{DESAFIOS NA FORMAÇÃO, CONVERSÃO E ATUAÇÃO DOCENTE}

\section{Alexandre Azenha Alves de Rezende Luciana Karen Calábria}

A expansão das universidades, marcada pelo Programa de Apoio a Planos de Reestruturação e Expansão das Universidades Federais (Reuni), teve como objetivo principal criar condições para a ampliação do acesso e permanência na educação superior, no nível de graduação presencial, aproveitando de forma mais adequada a estrutura física e os recursos humanos existentes nas universidades federais. Essa universidade pública é reconhecida por sua excelência na produção de conhecimento e ainda, é imbuída do compromisso de promover o desenvolvimento humanístico, social e científico, bem como realizar ações além de seus muros, reforçando o seu compromisso social. Manter essa importante vocação é tarefa desafiadora na qual docentes e discentes estão inseridos.

A formação docente é mais ampla do que a atualização pedagógica, didática ou mesmo científica (FAVARIN, 2014) e esse processo consiste em reflexões sobre as relações entre a teoria e a prática pedagógica, favorecendo o entendimento do processo de devir professor, buscado desde o início do processo formativo, e que precisa da construção de estratégias sistematizadas para a efetiva docência no futuro profissional. 
Neste contexto, a escrita cartográfica experimentada nos componentes curriculares "Projeto Integrado de Prática Educativa I (PIPE I)" e "Projeto Interdisciplinar I (PROINTER I)", bem como a vivência do método científico e todas as suas nuances no componente curricular "Pesquisa em Educação", ambos no curso de licenciatura em Ciências Biológicas da Universidade Federal de Uberlândia, campus Pontal, teve como objetivo trazer o propósito da reflexão do "devir professor", não na perspectiva técnica, mas do entendimento da sua proposição mais ampliada, levando em consideração as individualidades e - aspecto biopsicosociocultural de cada estudante nas diferentes abordagens.

Durante os componentes curriculares PIPE I e PROINTER I foram cartografadas pelos discentes as visões que possuíam de si mesmos, a relação com o espaço da escola e com os professores e, numa perspectiva mais ampliada, como viam sua atuação profissional no futuro. O contato com as produções possibilitou ao docente entender as particularidades escondidas na generalidade do tratamento da sala de aula. Ter o conhecimento de que muitos ingressaram sem saber se queriam ser professores/as ou mesmo se Ciências Biológicas seria o curso a ser vencido, muitas vezes era revelado na execução das atividades como um provável desinteresse. Por outro lado, em Pesquisa em Educação foi oportunizado aos discentes explorar e investigar os aspectos científicos dentro, fora e na interface da escola, respondendo as inquietações 
individuais e coletivas, e muitas vezes colocando-os/as em contato com o cenário vivido e retratado no memorial cartográfico.

A construção da identidade docente e, ao mesmo tempo do curso de licenciatura em Ciências Biológicas, é necessária. Ao ingressarem, muitos ainda trazem o entendimento de que a docência é um dom/vocação e não um processo formativo. Paulo Freire já questionava esse "dom" ao escrever: "Ninguém nasce educador ou marcado para ser educador. A gente se faz educador, a gente se forma, como educador, permanentemente, na prática e na reflexão sobre a prática (Freire, 1991, p. 58)”. O processo formativo do educador é complexo, principalmente quando se tem por objetivo a mudança de paradigma e a transformação da prática pedagógica, colocando a pesquisa como um dos pilares desse processo.

Contudo, as vivências docentes até o momento reforçam o compromisso social da universidade no que tange a formação técnico-científica e na consolidação de uma sociedade mais democrática. Por outro lado, para atingir esse objetivo é necessário ressignificar os papéis docente-discente, visando como resultado final um profissional ético, competente e responsável em todas as nuances. 


\section{REFERÊNCIAS}

FAVARIN, Eneida do Amaral. A formação de professores e os desafios encontrados na entrada da carreira docente. In: Anais do X ANPED Sul, 2014, Florianópolis. X ANPED Sul. Florianópolis, 2014. p. 01-18.

FREIRE, Paulo. A educação na cidade. São Paulo: Cortez, 1991. 
OS PROGRAMAS DE FORMAÇÃO INICIAL DE

PROFESSORES DE CIÊNCIAS: POSSIBILIDADES PARA

ARTICULAÇÃO ENTRE A EDUCAÇÃO BÁSICA E O ENSINO

SUPERIOR

Ariane de Souza Siqueira

Na formação dos licenciandos, a docência e a gestão educacional devem ser concebidas de forma integrada, tentando superar a visão fragmentada e simplista de prática pedagógica (CARVALHO, 2017). Nessa direção, os programas institucionais de formação inicial de professores, como os Estágios Supervisionados, o PIBID e o PRP (Programa de Residência Pedagógica), proporcionam cenários adequados para a inserção dos licenciandos na dinâmica escolar.

Atuando como co-formadora nesses programas - PIBID, PRP e Estágios Supervisionados - pude vivenciar como as propostas planejadas e desenvolvidas junto aos graduandos podem colaborar para uma formação crítica e participativa, permitindo que os mesmos atuem como protagonistas durante sua formação profissional e desenvolvam meios para a resolução de problemas e conflitos oriundos do ambiente escolar. Inseridos na rotina, os graduandos passam a conhecer a realidade e dinâmica da escola, reconhecendo que muitas questões que atravessam a sala de aula podem se originar de outros espaços de convivência, como corredores, pátio, cantina, 
recepção, banheiros, entre outros. Conforme exposto por Carvalho (2017, p.13), "é necessário problematizar as ações docentes para que as observações possam, a partir de referenciais teóricos, ser significativas para os futuros professores, levando-os a refletir sobre a relação tão complexa entre $\mathrm{o}$ ato de ensinar de um professor e a aprendizagem de seus alunos".

Os programas de formação inicial de professores permitem a aproximação entre o ensino superior e a educação básica, podendo resultar tanto na qualidade da produção acadêmica quanto na melhoria da prática educativa na educação básica (SILVA, 2012). Como professora da educação básica de um colégio de aplicação vinculado à rede federal de ensino, minha atuação docente é orientada pelos princípios da indissociabilidade entre ensino, pesquisa e extensão. Assim, ao supervisionar os licenciados, incentivo os mesmos a participarem de ações de extensão e pesquisa que estão sendo desenvolvidas com e pela escola. Com isso, os futuros professores têm a oportunidade de enxergar que a prática docente na educação básica representa um campo de experimentações e possibilidades, reconhecendo que não é apenas na academia que circula o conhecimento. Rosa (2012) afirma que se o ensino, a extensão e a pesquisa forem articulados com as reais necessidades sociais e culturais é possível construir um circuito interativo, produzindo outros conhecimentos a partir da experiência. 
A proposta pedagógica para o ensino de Ciências que orienta minha prática docente pauta-se na Alfabetização científica (CHASSOT, 2018), almejando a formação cidadã de estudantes para o domínio e uso dos conhecimentos científicos e seus desdobramentos nas mais diferentes esferas de sua vida. Nessa direção, as metodologias desenvolvidas e aplicadas por minha área de ensino são orientadas pelo enfoque CTSA (Ciência, Tecnologia, Sociedade e Ambiente).

Durante a formação inicial, os estudantes da graduação tiveram a oportunidade de atuar como monitores em eventos promovidos pela escola e a participar de grupos de estudos, orientando discentes da educação básica em atividades de pesquisa. A participação dos licenciandos nessas atividades contribuiu significativamente para a formação dos mesmos, pois eles tiveram a oportunidade de exercitar a escrita científica, elaborando resumos, resumos expandidos e trabalhos completos para inscrição em eventos científicos. Ademais, como exposto na obra organizada por Carvalho (2018) a literatura tem mostrado a força das concepções epistemológicas dos professores sobre a natureza da Ciência que ensinam e de como ensinam e a influência dessas representações nas decisões sobre o que ensinar e quais práticas adotar. 


\section{REFERÊNCIAS}

CARVALHO, Anna Maria Pessoa de. Os estágios nos cursos de licenciatura. São Paulo: Cengage Learning, 2017.

CARVALHO, Anna Maria Pessoa de (Org). Ensino de ciências: unindo a pesquisa e a prática. São Paulo: Cengage Learning, 2018.

CHASSOT, Attico. Alfabetização científica: questão e desafios para a educação. 8 ed. ljuí: Ed. Unijuí, 2018.

ROSA, Sônia Maria Oliveira da. A "nova" aliança entre a educação básica e o ensino superior: um avatar científico ou uma prática discursiva necessária? In: IX Seminário de Pesquisa em educação da região Sul: a pós-graduação e suas interlocuções com a educação básica (Anais...). Caxias do Sul, Universidade de Caxias do Sul. 2012. Disponível em: https://www.ucs.br/ucs/tplAnped2011/eventos/anped_sul_2012/anais/ Acesso em 27.08.2020. 


\section{O PROGRAMA INSTITUCIONAL DE BOLSA DE INICIAÇÃO À DOCÊNCIA - PIBID: POLÍTICA DE FORMAÇÃO SOB ATAQUE}

\section{Renata Carmo-Oliveira}

A implementação do Programa Institucional de Bolsa de Iniciação à Docência - PIBID, no ano de 2007, pela Coordenação de Aperfeiçoamento de Pessoal de Nível Superior (Capes) foi marco importante para nossa história no campo da formação de professores possibilitando sua inserção e provocando as mudanças na evolução social e escolar.

A formação de professores, exige atenção não somente com relação ao conhecimento científico e cultural, como também ao que envolve as questões metodológicas e práticas. Neste sentido, o PIBID se apresenta na busca de um espaço-tempo para uma formação profissional que seja planejada e desenvolvida pelos bolsistas diretamente envolvidos, bem como por profissionais ligados as licenciaturas em que esse programa se insere.

Desde sua implementação na Universidade Federal de Uberlândia, observa-se seu crescimento e visibilidade nos cursos de licenciaturas. São treze anos de um aprendizado, planejamento e desenvolvimento compartilhado no espaço escolar pelas instituições de ensino superior e da educação básica. 
Nos cursos de Ciências Biológicas da Universidade Federal de Uberlândia, acompanho o aprimoramento nas formas de orientar a formação, a construção da autonomia dos licenciandos, o retorno de egressos à Instituição e à continuidade na formação e, principalmente, a ênfase na importância da parceria com os colegas da educação básica na formação inicial de professores de Ciências e Biologia.

Mesmo com os desafios impostas pela organização para o tempo das ações, o PIBID se estabelece como um programa que aproxima as diferentes áreas não somente na perspectiva acadêmica, mas também na escolar. As atividades didático-pedagógicas, culturais e administrativas colocam os bolsistas em uma perspectiva de diálogo, muito importante para a formação e a ação docente. As diferenças e confrontos provocados pela busca e construção da autonomia, pela ação mais propositiva e investigativa encontram espaço para o diálogo e o trabalho coletivo, tão pertinentes para o processo ensino-aprendizagem e para a construção de um profissional politicamente mais atuante.

Apesar de desenhado para se estabelecer como uma política pública de formação de professores e entendido como um projeto inovador, o programa sempre sofreu com as críticas e disputas no campo político, econômico e até acadêmico. Mas, a despeito de minhas considerações, e avaliações tão positivas, não há como esconder, tais críticas que o Programa sofre pelas análises de pesquisadores que o consideram como um 
programa isolado dentro das licenciaturas não tendo objetivos e atividades comuns; o que faz com que não haja uma mudança na lógica de uma formação fragmentada que não supera a perspectiva individualista e competitiva da sociedade capitalista, não fortalecendo assim a política de formação de professores e até mesmo levando a precarização da formação. Mesmo com tais pesquisas, minha experiência como coordenadora de área no subprojeto de Ciências e Biologia e coordenadora institucional do programa, por cerca de dez anos, revela que o trabalho coletivo acontece e que aqueles que passaram pelo programa tiveram a chance de agregar valores no trabalho em equipe, na expressão política nos movimentos de luta pela manutenção do programa, no aprimoramento das relações e na ação docente mais planejada, reflexiva e propositiva. Estudos metodológicos, culturais e voltados a questões raciais, de gênero e diversidade se desenvolvem nas perspectivas dos inúmeros trabalhos elaborados como Parreira et al. (2014), Carmo-Oliveira et al. (2015), Costa e Costa (2015), Chelotti (2016), entre outros.

\section{REFERÊNCIAS}

BRASIL. Portaria Normativa $n^{\circ} 38$, de 12 de dezembro 2007. Instituiu o Programa Institucional de Bolsas de Iniciação à Docência (PIBID), aos discentes dos cursos de licenciatura para a docência no ensino médio. DOU: Brasília, DF, 13 dez 2007. Seção 1. 
CARMO-OLIVEIRA, Renata et al. Experiências e reflexões do PIBID Biologia UFU, 2015.

CHELOTTI, Marcelo Cervo. Diálogos do PIBID com as escolas do/no campo. 2016.

COSTA, Antônio Cláudio Moreira; COSTA, Maria Simone Ferraz Moreira. Diversidade cultural afro-brasileira e indígena. Uberlândia: UFU/PIBID/FACIP, 2015.

GATTI, Bernardete A. et al. Um estudo avaliativo do Programa Institucional de Bolsa de Iniciação à Docência (PIBID). São Paulo: FCC/SEP, v. 41, p. 3-120, 2014.

PARREIRA, Fátima Lúcia Dezopa et al. Diálogos sobre sexualidade: aproximações e distanciamentos nos discursos de licenciados/as de Ciências Biológicas bolsistas do PIBID/UFU. 2014 


\section{RE-EXISTÊNCIAS NA FORMAÇÃO DE PROFESSORES DE CIÊNCIAS E BIOLOGIA NO CONTEXTO DOS INSTITUTOS FEDERAIS}

\section{Gustavo Lopes Ferreira}

Desde o ano de 2010, vinha atuando como professor de Ciências do ensino fundamental, em Uberlândia-MG. Em meio a minha prática docente, durante o Mestrado em Educação no PPGED-UFU, acampei minha pesquisa nos espaços não formais de educação. Naquele período, eu não pesquisava dentro da minha escola. No entanto, após ter me tornado professor do Instituto Federal Goiano (IF Goiano) - campus Ceres, no ano de 2014 e ao ingressar no Doutorado em Educação em Ciências no PPGEduC-UnB, em 2016, a relação entre minha prática pedagógica e meu fazer investigativo se tornou real.

Minha imersão na Licenciatura em Ciências Biológicas como formador de professores me levou a querer pesquisar a formação de docentes de Ciências e Biologia no contexto dos IFs, passando a considerar estes espaços como novos lócus formativos. Na tese, busquei compreender o processo de formação inicial a partir de narrativas autobiográficas de professoras-egressas da Licenciatura em Ciências Biológicas do IF Goiano. 
Os 38 IFs foram criados no final do ano de 2008, através da Lei $n^{\circ} 11.892$ (BRASIL, 2008). A verticalização é um diferencial dos IFs em relação a outras Instituições de Ensino Superior (LIMA, 2012). Nesse sentido, essas instituições mantêm vínculos com suas origens na Educação Profissional e Tecnológica (EPT), respaldada na Lei de sua criação, que define que, no mínimo, $50 \%$ das vagas seja para a EPT de nível médio (BRASIL, 2008, Art. $8^{\circ}$ ).

Junto ao histórico compromisso com a EPT, os IFs se consolidaram como mais um lócus de formação de professores (CAMARGO; CASTRO, 2016). Legalmente, têm de ofertar, no mínimo, $20 \%$ de vagas em cursos de formação de professores (BRASIL, 2008, Art. 8).

Os IFs ainda podem ministrar cursos superiores de tecnologia, bacharelados, engenharias, especializações, mestrados e doutorados. Devido seu status de instituição universitária, as atividades de ensino, pesquisa e extensão, também estão em seu horizonte de atuação.

A interiorização do ensino promovida pelos IFs é outro aspecto marcante dessas instituições. Isso faz com que possam contribuir para ampliar o número de docentes da Educação Básica formados em nível superior, especialmente em localidades onde mais faltam professores graduados, o interior do País, nas cidades de pequeno porte.

Ao ampliar o lócus de formação de professores os IFs tornaram-se uma opção a mais de itinerário formativo, ao lado 
de outras instituições como universidades, faculdades e centros universitários públicos e privados. Os IFs têm uma longa tradição com a EPT, no entanto, a formação de professores é ainda novidade. É nesta direção que são realizadas críticas.

Não considero que a falta de tradição em formar professores seja um problema que desmereça o trabalho dos IFs. Historicamente, tais locais não foram criados com essa finalidade, porém ao longo do tempo foram sendo aproveitados para a formação docente. Nesse processo, utilizou-se, segundo Lima (2012), toda a pré-existência de infraestrutura e recursos humanos (docentes, técnicos administrativos) destinados à EPT para a formação de professores.

Tomando a realidade histórica pela qual o Brasil atravessa desde o ano de 2016, com o impeachment da presidenta Dilma Roussef, culminando com a eleição de 2018, na qual a extrema-direita saiu vencedora, o cenário é desanimador. Temos vivido um verdadeiro ataque à Educação e seus profissionais. A formação inicial e continuada de professores tanto nos IFs quanto nas universidades atravessa momentos difíceis. Mais do que nunca, é preciso que as instituições comprometidas com a formação docente do nosso país sigam juntas em RE-EXISTÊNCIA. 


\section{REFERÊNCIAS}

BRASIL. Congresso Nacional. Lei no 11.892, de 29 de dezembro de 2008. Institui a Rede Federal de Educação Profissional Científica e Tecnológica e dá outras providências. Diário Oficial [da] República Federativa do Brasil, Poder Executivo, Brasília, DF, 30 dez. 2008, Seção 1, p. 1.

CAMARGO, Arlete Maria Monte; CASTRO, Alda Maria Duarte Araújo. Expansão da Educação Superior e formação de professores nos estados do Pará e do Rio Grande do Norte. Educação em Revista, Belo Horizonte, v. 32, n. 04, p. 119-146, out./dez. 2016.

LIMA, Fernanda Bartoly Gonçalves. A formação de professores nos Institutos Federais de Educação, Ciência e Tecnologia: um estudo da concepção política. 2012. 282 f. Dissertação (Mestrado em Educação) Faculdade de Educação da Universidade de Brasília (UnB), Brasília, 2012. 


\section{MEMÓRIAS DA INFÂNCIA À PROFISSÃO DOCENTE: HISTÓRIAS DE UMA PROFESSORA DE BIOLOGIA}

Tiessa Lorraine Miguel da Silva

Iniciei meus estudos com cinco anos de idade e prossegui o ensino fundamental e médio em escolas públicas. Lembro-me de muitos aprendizados adquiridos em todo esse tempo, não somente de conteúdos escolares, mas daquilo que ficou internalizado como conselhos, afetos adquiridos pela socialização escolar.

Os professores tiveram um papel fundamental, o de orientar e incentivar a nós alunos a prosseguir nos estudos. Ainda que na época a realidade não fosse favorável, eu tinha um sonho de cursar uma faculdade. Nunca desisti e meus pais também foram o alicerce fundamental para que eu prosseguisse nos estudos.

Chegando à época de cursar uma faculdade tomei conhecimento sobre o Curso de Ciências Biológicas, era uma graduação nova na região. Identifiquei-me pela área e por ser também licenciatura. Prestei vestibular e passei. No Curso fui me identificando com os conteúdos, com o lugar acolhedor do campus Ceres do IF Goiano. No entanto, tive dificuldades e reprovei em algumas disciplinas. Porém, foi a partir desse acontecimento que me dediquei aos estudos com mais responsabilidade. 
A experiência dos Estágios Curriculares Supervisionados considero como o momento decisivo do Curso, pois foram as ocasiões em que coloquei em ação toda a parte teórica agregada com o tempo. Estar a frente de uma sala de aula, me fez ter a certeza de que eu estava no caminho certo e que a minha formação poderia contribuir com aquele contexto escolar que experienciei.

Participei da pesquisa de doutorado do meu exorientador e professor Gustavo Lopes Ferreira, intitulada "Compreendendo a formação de professores de Ciências e Biologia no Instituto Federal Goiano: uma abordagem biográfica com seus egressos", na qual junto com outras egressas do curso, produzimos e trocamos experiências por meio de narrativas autobiográficas. Nesse processo, percebi em comum com outras colega-professoras a forte identificação com a docência no contato com a sala de aula durante os Estágios.

Ao longo de todos os encontros do grupo da pesquisa foram relatadas muitas histórias que vivenciamos durante nossa formação inicial em Ciências Biológicas. Mesmo estando juntas fisicamente na época, muitos dos acontecimentos vivenciados eu não consegui compreender. Somente após a escrita e a partilha das narrativas e dos encontros é que ouvi os relatos e eles trouxeram mais clareza aos fatos contados. Dessa maneira, aprendi a ouvir a história do outro com mais empatia.

$\mathrm{Na}$ escrita das minhas narrativas autobiográficas tive dificuldade em selecionar os fatos que contribuíram de maneira 
significativa na minha formação, pois muitos foram os acontecimentos que se acumularam ao longo do tempo. O que me fez refletir sobre como cada uma de nós enquanto professoras reage à determinadas situações que nos acometem. Trazemos conosco experiências e sentimentos que nos singularizam, traçamos caminhos diversos, muitos desconhecidos pelos outros. No momento da partilha, de ouvir o outro e durante a edição das narrativas alcançamos uma melhor compreensão das vivências e pudemos refletir sobre as experiências narradas.

A experiência com as narrativas pode impactar a formação de professores à medida que por meio dessas histórias, nós docentes podemos nos expressar e assim, olhar para a nossa própria formação, através das experiências que vivenciamos cotidianamente, da realidade social na qual estamos imersos. Após escrever e partilhar minhas narrativas percebi que elas são potentes instrumentos que nos permite uma reflexão pedagógica e assim, a compreensão da atuação docente e a criação de novas estratégias pedagógicas. A narrativa favorece o processo de interação com o outro, de compreender o papel de cada um na vida do outro (GALVÃO, 2005).

Apesar de ainda não atuar na profissão docente, projeto a profissional que quero ser com as lembranças que guardo das experiências escolares e aquelas vivenciadas nos Estágios. Recordo-me que em sala de aula presenciei diferentes 
realidades. Desse modo, busquei conhecer a história e compreender a realidade vivenciada fora do contexto escolar pelos 42 alunos da turma de ensino fundamental. Isso foi um diferencial. Ainda que eu seja uma profissional que almeje dominar os fundamentos teóricos, não posso me esquecer das minhas origens e do contexto social em que estamos inseridos. Como seres distintos, fazedores de histórias, somos formadores e o processo narrativo contribui para formar e expor nossa identidade, refletir sobre ela com a finalidade de reformulá-la.

\section{REFERÊNCIAS}

GALVÃO, Cecília. Narrativas em Educação. Ciência \& Educação, v. 11, n. 2, p. 327-345, 2005. 


\section{A ASSOCIAÇÃO BRASILEIRA DE ENSINO DE BIOLOGIA (SBENBIO) E A FORMAÇÃO DE PROFESSORAS E PROFESSORES: POR ONDE CAMINHAMOS}

\section{Leandro Duso}

A importância das associações científicas decorre delas gerarem e preservarem a História da Ciência e das Profissões relacionadas, de criarem estímulos e condições de desenvolvimento, quer da ciência, quer da profissão.

A SBEnBio é uma associação civil de caráter científico e cultural que visa promover o desenvolvimento do ensino de Biologia e da pesquisa em ensino de Biologia entre profissionais desse campo de conhecimento e de áreas afins, sem fins lucrativos e sem qualquer vinculação político-partidária ou religiosa.

Desde sua fundação, em julho de 1997, durante o VI Encontro Perspectivas do Ensino de Biologia (EPEB), na USP, a associação vem participando da discussão e debatendo a formulação, execução e avaliação de políticas públicas de educação, contribuindo para uma análise crítica das ações realizadas no setor e zelando pelos interesses comuns dos docentes da educação básica, educadores e pesquisadores em ensino de ciências e biologia.

Estamos ampliando a rede de relações entre as/os profissionais da área, fomentando a comunicação da 
comunidade e mobilizando o debate sobre temas pertinentes ao ensino de Biologia por meio de iniciativas virtuais e presenciais. Sempre temos como horizonte a valorização da participação de professores e professoras da Educação Básica e dos/as estudantes de Licenciaturas, nos eventos nacionais, como o Encontro Nacional de Ensino de Biologia (ENEBio), além de estimular a realização dos Encontros Regionais de Ensino de Biologia (EREBios), organizado pelas seis (6) regionais que compõem a associação.

Desde 2005, a associação mantém a Revista Brasileira de Ensino de Biologia (REnBio), periódico que constitui um dos principais espaços de diálogo da comunidade de professoras e professores de Biologia no país, divulgado práticas e pesquisas de qualidade na área do ensino de Ciências e Biologia.

Em relação a formação de professores podemos destacar que a REnBio "tem por objetivos divulgar artigos que dialoguem com situações concretas de sala de aula e com a produção acumulada na área, constituindo-se como um espaço de diálogo para Professores da Educação Básica, Licenciandos, Pós-Graduandos e Professores do Ensino Superior na área de Ensino de Biologia." (SBEnBio, 2020). A REnBio continua sendo o único periódico brasileiro destinado especificamente para a divulgação de trabalhos da área de ensino de Biologia.

A SBEnBio, é filiada à Sociedade Brasileira para o Progresso da Ciência (SBPC), atuando no GT de Educação Básica, que vem discutindo as políticas públicas da área de 
ensino. Também somos filiados ao Fórum Nacional Popular de Educação (FNPE), participando das plenárias na luta por uma educação pública de qualidade.

Estamos atuando na formação de uma rede de comunicação com outras instituições científicas, liderada pela ANPED, com o objetivo de buscar reunir esforços para atuar no campo da comunicação pública da pesquisa. Há poucos veículos institucionais que permitem a nossa participação no debate público sobre os sentidos da educação, de divulgação da pesquisa para o público não especializado e de promoção do diálogo sistemático entre a universidade e a escola básica e entre os(as) pesquisadores(as) dos programas de pós graduação e os(as) profissionais da escola básica. Nesta perspectiva a "Rede Comunica Educação" que buscará reunir esforços para atuar no campo da comunicação pública da pesquisa.

Para aproximar os associados e o público em geral, temos o site como principal canal de comunicação, onde se pode encontrar as notas relacionadas a área de Ensino de Biologia e Educação, informações de eventos entre outras informações relevantes da área. Quinzenalmente a SBEnBio envia para os associados, via e-mail, informativo "SBEnBioNews" com o objetivo de divulgação das ações da associação nacional e das seis regionais, além de outras entidades da área.

Se quiser saber mais sobre as ações da SBEnBio, acesso nosso site <https://sbenbio.org.br/>, busque 
informações da regional da sua região e se junte a nós para continuarmos atuando por uma educação pública e de qualidade.

\section{REFERÊNCIAS}

SBENBIO, c2018. Página inicial. Disponível em: https://sbenbio.org.br. Acesso em: 31 de ago. de 2020. 


\section{O SISTEMA CFBIO/CRBIOS E O BIÓLOGO-EDUCADOR}

Atenágoras Carvalhais

Mariana Telles

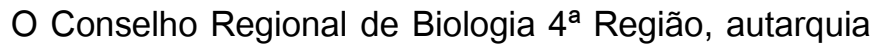
federal com jurisdição nos Estados de Minas Gerais, Goiás, Tocantins e no Distrito Federal, integra o Sistema CFBio/CRBios, que detém privativamente as funções de fiscalizar, normatizar e orientar o exercício profissional dos biólogos, profissão criada pela Lei n $6.684 / 79$ (alterada pela Lei $n^{\circ} 7.017 / 82$ e regulamentada pelo Decreto $n^{\circ} 88.438 / 83$ ).

A atuação do Sistema CFBio/CRBios é ferramenta imprescindível que visa assegurar o direito de exercício profissional dos biólogos e garantir à sociedade a qualidade e competência técnica na realização dos trabalhos desses profissionais, os quais muitas vezes se relacionam à educação.

No entanto, é necessário distinguir a atuação técnica como biólogo da atuação como professor. A primeira requer obrigatoriamente o registro do graduado em biologia junto ao CRBio, sendo inclusive o título de biólogo reservado exclusivamente aos profissionais registrados. No segundo caso, do profissional com atuação exclusiva na docência, o registro é facultativo, devido ao exercício da docência ser normatizado e acompanhado principalmente pelas Secretarias Municipais e Estaduais de Educação, além do Ministério de Educação. 
Por outro lado, sabendo que muitos biólogos atuam também como educadores (em espaços de ensino formais e informais), e com vistas a possibilitar o desenvolvimento de ações conjuntas relacionadas à educação e formação de professores no âmbito da biologia, a atual Gestão do CRBio-04 (2019-2023) propõe uma série de projetos pensados para esses profissionais. São eles:

- Encaminhamento ao CFBio de proposta de Resolução com desconto na anuidade para profissionais que atuem exclusivamente como docentes no ensino básico e superior;

- Criação do Prêmio Biólogo-Educador, a ser lançado em 2021, fomentando projetos inovadores no ensino de ciências e biologia para professores e escolas regularmente registrados no $\mathrm{CRBio-04;}$

- Desenvolvimento de cursos de atualização para professores, em parceria com Associações e Instituições de Ensino Superior;

- Criação de Comissão Técnica em Educação no CRBio04 para receber, apreciar e processar demandas específicas da área, bem como prestar assessoria à Diretoria;

- Manutenção do Programa de Apoio a Publicações e Eventos (PAPE), destinado a pessoas jurídicas sem fins 
lucrativos com iniciativa de interesse no âmbito da biologia.

Importante destacar também que os Conselhos de Classe, justamente por terem natureza autárquica, possuem competências de ação limitadas pelas leis que os criam, sendo necessário o fomento e criação de outras entidades de classe, tais como Sindicatos e Associações, para melhor atendimento às demandas diversas da categoria.

Assim, fica como mensagem final ressaltada a importância do registro e agremiação de profissionais nas variadas entidades de classe, independentemente de ser ou não um ato obrigatório, pois será por meio desses fortalecimentos institucionais que serão promovidos ganhos e mantidos direitos da categoria. Além disso, o fortalecimento e a importância da profissão são dependentes do engajamento real desses profissionais nas diversas entidades de classe e esferas da sociedade.

\section{REFERÊNCIAS}

BRASIL. Lei $n^{\circ} \mathbf{6 . 6 8 4}$, de 3 de setembro de 1979. Regulamenta as profissões de Biólogo e de Biomédico, cria o Conselho Federal e os Conselhos Regionais de Biologia e Biomedicina, e dá outras providências. Disponível em:

http://www.planalto.gov.br/ccivil_03/leis/1970-1979/L6684.htm. Acesso em: 31 de ago. 2020. 
BRASIL. Lei $n^{\circ}$ 7.017, de 30 de agosto de 1982. Dispõe sobre o desmembramento dos Conselhos Federal e Regionais de Biomedicina e de Biologia. Disponível em:

http://www.planalto.gov.br/ccivil_03/LEIS/L7017.htm. Acesso em: 31 de ago. 2020.

BRASIL. Decreto $\mathbf{n}^{\circ} \mathbf{8 8 . 4 3 8}$, de 28 de junho de 1983. Dispõe sobre a regulamentação do exercício da profissão de Biólogo, de acordo com a Lei $n^{\circ} 6.684$, de 3 de setembro de 1979 e de conformidade com a alteração estabelecida pela Lei $n^{\circ} 7.017$ de 30 de agosto de 1982. Disponível em: http://www.planalto.gov.br/ccivil_03/decreto/1980-1989/D88438.htm. Acesso em: 31 de ago. 2020. 


\section{AUTORES E AUTORAS:}

Alexandre Azenha Alves de Rezende - Biólogo e Doutor em Genética pela Universidade Federal de Uberlândia (UFU). Docente do Instituto de Ciências Exatas e Naturais do Pontal, UFU, atuando nos cursos de bacharelado e licenciatura em Ciências Biológicas. E-mail: azenha@ufu.br.

Ana Isa Marquez Rocha Machado - Licenciada e Bacharel em Ciências Biológicas pela Universidade Federal de Uberlândia. Mestre em Biologia Vegetal pelo Programa de Pós-Graduação em Biologia Vegetal - UFU. Professora do Ensino Básico, Técnico e Tecnológico do Instituto Federal de Educação, Ciência e Tecnologia do Triângulo Mineiro - Campus Uberaba. Atualmente ministra aulas nos cursos de Bacharelados em Engenharia Agronômica e Zootecnia e Licenciatura em Ciências Biológicas. Está como Coordenadora Institucional do Pibid/IFTM - edital 2020. E-mail: anaisa@iftm.edu.br.

Ariane de Souza Siqueira - Docente do CAp.Eseba/UFU: Colégio de Aplicação da Universidade Federal de Uberlândia - campus Educação Física. E-mail: ariane.siqueira@ufu.br.

Atenágoras Café Carvalhais Jr. - Graduado em Ciências Biológicas pela UFMG e Mestre em Ecologia pela mesma Instituição. Trabalha no CRBio-04 desde 2010, onde atuou principalmente no Setor de Fiscalização. A partir de 2019, passa responder pela Assessoria Institucional do Conselho. E-mail: institucional@crbio04.gov.br.

Fátima Lucia Dezopa Pareira - Doutora em educação pela Universidade Federal de Uberlândia. Professora da Educação Básica, lotada na Secretaria de Estado de Educação de Minas Gerais. E-mail: dezopafatima@gmail.com.

Gustavo Lopes Ferreira - Professor do IF Goiano; Doutorando em Educação em Ciências (PPGEduC/UnB); Mestre em Educação (PPGED/UFU). Licenciado e Bacharel em Ciências Biológicas (UFU). E-mail: gustavolofer@gmail.com.

Mariana Pires de Campos Telles - Graduada em Ciências Biológicas (Bacharelado), Mestre em Agronomia e Doutora em Ciências Ambientais pela UFG. Professora e Pesquisadora na PUC Goiás e na UFG. Delegada do CRBio04 em Goiás, desde 2019. E-mail: tellesmpc@gmail.com.

Matheus Moura Martins - Licenciado em Ciências Biológicas no Instituto de Ciências Exatas e Naturais do Pontal, Universidade Federal de Uberlândia 61| 
campus Pontal e mestrando do Programa de Pós-Graduação em Educação, Universidade Federal de Uberlândia. E-mail: matheusmmm12@yahoo.com.br.

Leandro Duso - Doutor em Educação Científica e Tecnológica da Universidade Federal de Santa Catarina. e-mail: dusoleandro@gmail.com.

Luciana Karen Calábria - Bióloga e Doutora em Bioquímica pela Universidade Federal de Uberlândia (UFU). Docente do Instituto de Ciências Exatas e Naturais do Pontal, UFU, atuando nos cursos de bacharelado e licenciatura em Ciências Biológicas e Química. E-mail: Ikcalabria@ufu.br.

Renata Carmo-Oliveira - Graduada em Ciências Biológicas/Licenciatura pela Universidade Federal de Uberlândia. Pós-graduada em Botânica. Atua na área de anatomia vegetal e formação de professores de Ciências e Biologia. Coordenadora Institucional do PIBID/UFU e do Laboratório de Ensino de Ciências e Biologia INBIO/UFU. E-mail: carmoliveira@ufu.br.

Tiessa Lorraine Miguel da Silva - Licenciada em Ciências Biológicas pelo Instituto Federal Goiano - Campus Ceres. E-mail: tiessa77@gmail.com.

Viviane Rodrigues Alves de Moraes - Graduada em Ciências Biológicas pela Universidade Federal de Uberlândia (UFU), mestra em Genética e Bioquímica pela UFU e Doutora em Educação em Ciências e Matemática pela Universidade de São Paulo (USP). Professora do Instituto de Biologia (INBIO/UFU) do Núcleo de Educação. E-mail: vivimoraes@ufu.br.

\section{Organizadores:}

\section{Sandro Prado Santos}

Minha formação é em Ciências Biológicas com efervescentes contágios pela educação em Biologia. Doutor em Educação, professor da Universidade Federal de Uberlândia e Pós-doutorando em Educação por essa mesma instituição, onde prolifera-se pelas linhas que compõem biologias, gêneros, corpos e sexualidades.

\section{Gustavo Lopes Ferreira}

Sou biólogo, porém não moro na casa dessa Ciência o tempo inteiro. Atuo como formador de professores na Licenciatura em Ciências Biológicas do IF Goiano. Ensino Biologia no Ensino Médio também nesse Instituto. Sou doutorando em Educação em Ciências (UnB); mestre em Educação (UFU) e bacharel e licenciado em Ciências Biológicas (UFU). 


\title{
Sobre o Ebook
}

\author{
Tamanho $14 \times 21 \mathrm{~cm}$ \\ Formato Digital \\ Extensão PDF \\ Capa: Duo color \\ Miolo: $\quad \mathrm{P} \& \mathrm{~b}$ \\ Tipografia: Utsaah
}

\author{
Editora Culturatrix \\ - publicações acadêmicas - \\ www.culturatrix.com
}

Diagramado por Studio Escrita \& Criação, Uberlândia, MG 
Um caderno-re-existência. Um acon-tecimento coletivo em 12 textos com pequenos e desafiadores exercícios de escrita, educativas, atravessados por reflexões teóricas, narrativas, experienciações, lutas, afetos, sensibilidades, inter(in)venções, desafios, diferentes espaços-tempos formativos que re-existem, acolhem e tornam possível a educação e a formação em Ciências e Biologia, fazendo proliferar re-existências frente contexto das políticas educacionais brasileiras. 